\title{
PERCEPÇÃO DE ACADÊMICOS DE ENFERMAGEM E MEDICINA SOBRE FRAGILIDADES NA ATENÇÃO AO POTENCIAL DOADOR DE ÓRGÃOS
}

\section{PERCEPTION OF ACADEMIC NURSING AND MEDICINE ON WEAKNESSES IN CARE TO THE POTENTIAL ORGAN DONOR}

\section{LA PERCEPCIÓN DE LA ENFERMERÍA Y LA MEDICINA ACADÉMICA EN LAS DEFICIENCIAS EN LA ATENCIÓN AL DONANTE POTENCIAL DE ÓRGANOS}

\author{
Maria Samara Vasconcelos Cisne ${ }^{1,}$ José Jeová Mourão Netto ${ }^{2,}$ Taciane Correia dos Santos ${ }^{3,}$ Maria \\ da Conceição Coelho Brito ${ }^{4,}$ João Sérgio Araújo Soares ${ }^{5,}$ Natália Frota Goyanna ${ }^{6}$
}

\begin{abstract}
RESUMO
Objetivo: conhecer as dificuldades na manutenção do potencial doador de órgãos e tecidos, a partir dos discursos dos acadêmicos envolvidos. Métodos: pesquisa qualitativa, do tipo exploratório-descritiva, realizada com estudantes de enfermagem e medicina membros de uma comissão de Organização de Procura de Órgãos de um Hospital de Referência no Estado do Ceará. A Coleta de informações ocorreu por entrevista semiestruturada. Os resultados foram analisados conforme a técnica de categorização. Resultados: Emergiram três categorias: Trabalho desenvolvido pela Organização de Procura de Órgãos, opinião dos bolsistas quanto ao trabalho exercido e entraves no processo de manutenção do potencial doador. Conclusão: Observou-se que os principais entraves na manutenção do potencial doador são os recursos físicos e humanos do hospital.
\end{abstract}

Palavras-Chave: Obtenção de tecidos e órgãos; Morte encefálica; Transplante de órgãos.

\begin{abstract}
Objective: To know the difficulties in maintaining the potential donor organs and tissues, from the speeches of academic. Methods: Qualitative research, exploratory-descriptive, held with eight students of nursing and medicine Organ Procurement Organization members of a Reference Hospital. Collections made through semi-structured interviews and results analyzed according to categorization technique. Results: Taken three categories: Work developed by the Organ Procurement Organization, the opinion of scholars on the work carried out and barriers in the potential donor maintenance process. Conclusion: It was observed that the main obstacles in maintaining the potential donor are the physical resources and human hospital.

Keywords: Tissue and organ procurement; Brain Death s; Organs transplantation.

\footnotetext{
${ }^{1}$ Enfermeira. Discente da Especialização em Terapia Intensiva para Fisioterapeutas e Enfermeiros. Escola de Saúde Pública do Ceará (ESP/CE). Sobral, Ceará, Brasil. E-mail: samarahcisne@ @otmail.com

${ }^{2}$ Enfermeiro. Mestre em Saúde da Família. Docente da Especialização em Terapia Intensiva para Fisioterapeutas e Enfermeiros. Escola de Saúde Pública do Ceará (ESP/CE). Sobral, Ceará, Brasil. E-mail: jeovamourao@ yahoo.com.br .

${ }^{3}$ Enfermeira. Hospital Regional Norte. Sobral, Ceará, Brasil. E-mail: taciane00@ hotmail.com

${ }^{4}$ Enfermeira. Mestre em Saúde da Família. Docente do Curso de Enfermagem da Universidade Estadual Vale do Acaraú (UVA). Sobral, Ceará, Brasil. E-mail: marycey@ hotmail.com

${ }^{5}$ Enfermeiro. Mestre em Saúde da Família. Hospital Regional Norte. Sobral, Ceará, Brasil. E-mail: joaosergioaraujo@gmail.com

${ }^{6}$ Enfermeira. Discente do Programa de Mestrado em Saúde da Família da Universidade Federal do Ceará (UFC). Sobral, Ceará, Brasil. E-mail: nataliagoyanna@yahoo.com.br.
} 


\section{RESUMEN}

Objective: conocer las dificultades en el mantenimiento de los potenciales donantes de órganos y tejidos, a partir de los discursos de los académicos involucrados. Métodos: La investigación cualitativa, exploratoria y descriptiva, realizada con estudiantes de enfermería y medicina de una comisión de la Organización de Deamanda de Órgano de un hospital de referencia en el Estado de Ceará. La recogida de información se produjo por entrevista semiestructurada. Los resultados se analizaron según la técnica de categorización. Conclusión: Se observó que los principales obstáculos para el mantenimiento del donante potencial son los recursos físicos y humanos del hospital.

Palavras clave: Obtención de tejidos e órganos; Muerte encefálica; Transplante de órganos.

\section{INTRODUÇÃO}

A morte encefálica (ME) é definida como parada completa e irreversível das funções encefálicas, impossibilitando a manutenção da vida sem o auxílio de meios artificiais. ${ }^{1}$ Para a confirmação do diagnóstico de ME é indispensável à realização de dois exames neurológicos, que devem ser efetuados por dois médicos diferentes, um deles obrigatoriamente neurologista ou neurocirurgião. É obrigatória também a realização de exame complementar, para mostrar ausência de atividade elétrica e metabólica encefálica ou de perfusão sanguínea encefálica. ${ }^{2}$

O Brasil iniciou a realização de transplantes de órgãos no início na década de 60 , no entanto, àquela época, esse tratamento pouco se difundiu em razão da baixa sobrevida dos pacientes transplantados. Entretanto, após 15 anos, a atividade ganhou importância com o desenvolvimento e criação de técnicas cirúrgicas, equipamentos de suporte, métodos de determinação de histocompatibilidade entre doador e receptor e, finalmente, com o advento dos fármacos imunossupressores. Por fim, esses procedimentos difundiram-se entre estabelecimentos hospitalares, aumentando a necessidade de regulamentação para a doação e transplante de órgãos. ${ }^{3}$

Durante o ano de 2013, no Brasil, foram registrados 8.871 casos de $\mathrm{PD}$, de forma que somente 2.526 se tornaram efetivos, perfazendo um total de 6.345 não doadores. Entre as principais causas de não efetivação da doação, tem-se a recusa familiar (2.622), parada cardíaca (1.292) e a contraindicação médica (1.150). ${ }^{4}$

Após a identificação de um potencial doador, deve-se informar a família a suspeita da ME e realizar os exames comprobatórios. Em seguida, notifica-se o doador em potencial à Central de Notificação, Captação e Distribuição de Órgãos (CNCDO). E a 
mesma irá repassar a notificação à Organização de Procura de Órgãos (OPO), que por sua vez avalia as condições clínicas do potencial doador, e se viável realiza a entrevista familiar quanto à doação. Quando a família autoriza, inicia-se um protocolo interno que contempla vários procedimentos técnicos e administrativos indispensáveis para a viabilização dos órgãos.

Contudo, no cotidiano dos hospitais, se observa a dificuldade na manutenção adequada e eficaz quando se trata de um paciente em ME e, consequentemente, isto influencia no tempo de conclusão do diagnóstico, podendo interferir na decisão dos familiares quanto à doação. Outros fatores também podem influenciar o processo, como a fragilidade no conhecimento dos profissionais acerca da ME.

A atenção ao potencial doador de órgãos e tecidos também tem se mostrado um campo fértil para o aprendizado de estudantes de medicina e enfermagem, o que se mostra relevante, uma vez que apesar de muitas revisões curriculares nas instituições de nível superior, principalmente as da área da saúde, o tema ainda não é abordado de forma a garantir sua inserção de maneira consistente. $^{5}$

Acredita-se que o estudo poderá contribuir para a produção de conhecimentos nesta seara, podendo subsidiar mudanças na atenção fornecida. Infere-se também uma fragilidade na formação dos profissionais de saúde, pois boa parte dos cursos não apresenta oportunidade de um aprofundamento sobre o assunto em seus projetos pedagógicos.

A partir deste contexto, o presente estudo objetivou conhecer as dificuldades na manutenção do potencial doador de órgãos e tecidos, a partir dos discursos dos acadêmicos/bolsistas da OPO de um Hospital da Zona Norte do Ceará.

\section{Métodos}

Pesquisa exploratório-descritiva, com abordagem qualitativa do tipo estudo de campo, realizada em um Hospital de Referência da Zona Norte do Estado do Ceará, Brasil, que dispõe do serviço de manutenção, captação e transplante de órgãos e tecidos. O Hospital está localizado no Município de Sobral, distante $238 \mathrm{~km}$ da Capital, Fortaleza. Atualmente, é um dos hospitais de referência para uma população de cerca de 1,6 milhão de habitantes, compreendendo mais de 55 municípios da região e tem contribuído significativamente para o avanço de indicadores de transplantes, ocupando a terceira posição no Estado em número de notificações. ${ }^{6}$ 
O período de desenvolvimento do estudo foi compreendido entre os meses de julho de 2014 a maio de 2015. O início da coleta ocorreu após aprovação da Comissão de Ética em Pesquisa do Hospital e do Comitê de Ética e Pesquisa da Universidade Estadual Vale do Acaraú (UVA), com parecer de $n^{\circ} 1.058 .814$, em 04/03/2015, fazendo parte de uma pesquisa maior intitulada: Entraves no processo de manutenção de órgãos e tecidos: o que dizem os estudantes e profissionais envolvidos?

Participaram do estudo os bolsistas da equipe da OPO, composta por acadêmicos de enfermagem e medicina, em um total de 13 estudantes. Como critério de inclusão, deveriam estar na equipe há mais de 1 ano, assim, 8 bolsistas compuseram o grupo final de entrevistados.

Utilizou-se um roteiro para entrevista semiestruturada, sendo essas gravadas por meio de dispositivo eletrônico. Os depoimentos foram transcritos na íntegra e examinados na medida em que foram realizadas as coletas. Após a conclusão, os dados foram categorizados, correspondendo ao processo cognitivo de dividir as experiências do mundo em grupos de entidades, ou categorias, para construir uma ordem física e social do mundo. ${ }^{7}$ As falas de acadêmicos de enfermagem e medicina estão sinalizadas, respectivamente, por AE e AM seguidos de um numeral.

\section{Resultados e discussão}

Após análise das entrevistas, emergiram duas categorias: percepção sobre as atividades desenvolvidas na OPO $\mathrm{e}$ entraves no processo de manutenção do potencial doador $(\mathrm{PD})$.

\section{Percepção sobre as atividades desenvolvidas na OPO}

Nesta primeira categoria buscou-se apreender a percepção dos estudantes sobre as atividades realizadas na OPO. Nos depoimentos, os acadêmicos enfatizaram a manutenção adequada como um dos principais fatores para o sucesso de todo o processo, principalmente no momento da captação dos órgãos, pois a qualidade destes depende de como foi realizada a manutenção. Nosso trabalho é focado na manutenção dos órgãos, dentre outros esse é o mais importante, manter as funções vitais do paciente, mantendo os órgãos para que eles possam ser viáveis para uma possível doação (AE3). (...) a equipe de bolsistas inicia a monitorização e até a abertura do protocolo a fim de cuidar da qualidade da doação dos órgãos (AE4).

$\mathrm{O}$ foco dos bolsistas ao lidar com um PD é a manutenção hemodinâmica deste, em função das necessidades impingidas pela ME, que ocasiona alterações diversas no funcionamento dos órgãos. 
Os estudantes atribuem importância ao doador pelo fato deste congregar órgãos e tecidos que serão viáveis para utilização em outras pessoas. Apesar de o doador ser considerado clinicamente morto, não se referem a ele como um corpo, cadáver ou "coisa", mas como uma pessoa que apesar de morta, ainda necessita de cuidados, referindo-se a ela, então, como "paciente", embora se compreenda que não se cuida propriamente do cadáver, mas sim de seus órgãos, que irão beneficiar outros indivíduos. ${ }^{8}$

Relataram ainda o quanto é relevante para eles a oportunidade de serem integrantes da OPO, sendo significativo o aprendizado dos mesmos como futuros profissionais, já que, a partir dos relatos, a temática dos processos envolvidos na doação de órgãos parece estar fragilmente contemplada pelos projetos pedagógicos dos cursos da saúde. A OPO é o serviço que ajuda o estudante tanto de medicina como de enfermagem a se integrar com o processo de aprendizado em doação de órgãos, pondo em prática muitas atividades que ninguém vê na graduação. É um serviço que exige bastante desempenho do estudante, porque além de cumprir sua grade curricular tem que participar desses regimes de plantão. Entretanto, é um serviço que pode elevar muito o conhecimento (AM3).

Apesar de muitas revisões curriculares realizadas nas instituições de nível superior, principalmente as da área da saúde, o tema ainda é abordado de forma frágil e superficial, podendo se traduzir em uma fragilidade na atenção ${ }^{5}$, de forma que os estudantes podem estar em prejuízo, necessitando de oportunidades para sanar uma lacuna da formação.

O processo de educação torna-se fundamental nesta área, especialmente porque a participação da sociedade e, sobretudo dos profissionais de saúde, é um dos fatores decisivos do sucesso dos programas de transplante. Um grupo que merece destaque são os acadêmicos, especialmente da área da saúde. ${ }^{9}$

O melhor preparo dos profissionais ainda na academia poderia contribuir para melhoria do processo de manutenção e doação de órgãos, pois a capacitação dos profissionais sobre diagnóstico de ME e manutenção do PD pode aumentar o número de doadores, havendo a necessidade de desmistificar preconceitos, abordar mais profundamente as questões éticas, suprimir a carência de informações científicas e ampliar o número de indivíduos interessados, pois estes alunos, além de serem potenciais doares de órgãos, serão também os responsáveis por este mesmo papel perante os seus clientes/pacientes. $^{10-11}$

Procurou-se compreender também como os acadêmicos se sentem em relação a este trabalho. Os relatos evidenciam a 
compreensão da responsabilidade e dimensão social, sobressaindo-se ainda a contribuição dos bolsistas para a melhoria de indicadores da OPO. Eu vejo esse trabalho com grande importância, porque a gente não está cuidando só de uma vida (...) estamos cuidando de várias vidas (...), podendo beneficiar 3, 4 ou até mais vidas e também melhorar a qualidade de vida (...) (AE3). (...) mas sempre lembrar da melhora que a gente teve na manutenção dessas pessoas, que trouxeram além de maior número de captações, também uma melhora da qualidade dos órgãos que foram captados (AM2).

É positivo que o estudante se implique com as problemáticas do campo. Essas oportunidades vão ao encontro da integração ensino-serviço, que defende o desenvolvimento de competências dentro do campo de trabalho, principalmente enquanto ainda estudantes.

\section{Entraves no processo de manutenção do potencial doador}

A maioria dos estudantes afirmou a existência de entraves no processo de manutenção do potencial doador, dentre eles vale ressaltar problemas em relação à quantidade e qualidade dos profissionais que fazem parte da OPO e de outros provenientes do serviço, que muitas vezes tem que participar do processo, devido a escassez de profissionais, tanto médicos como enfermeiros, apesar de fragilidades na habilidade e conhecimento em relação ao tema. O número de médicos e a disponibilidade deveria ser maior, a abertura e o fechamento de protocolo torna-se muito demorado em virtude da escassez dos profissionais, além dos médicos a equipe de enfermagem também deveria está em maior número (...) (AM1). (...) tem a questão dos profissionais que não fazem parte da OPO, que não tem o conhecimento adequado e acabam atrapalhando também o processo (...). A OPO possui poucos profissionais que se dedicam exclusivamente ao serviço, eles ficam de plantão nos setores $e$, por terem outras tarefas, atrapalha todo o processo (AM2). (...) a gente percebe a necessidade da realização dos exames pelo médico clínico $e$ o neurologista ou neurocirurgião e muitas vezes eles são profissionais que estão escassos no serviço de saúde e acabam retardando a abertura e fechamento do protocolo (AM3).

Um doador pode beneficiar mais de dez pessoas, entretanto, no Brasil, as listas de espera vêm se ampliando a cada dia devido à escassez de órgãos. As fragilidades na atenção ao PD de órgãos e tecidos têm sido descritas na literatura como possíveis responsáveis para a não efetivação de parcela importante de doações, sejam estas ao nível estrutural, financeiro ou de recursos humanos. $^{12}$

Mesmo sabendo que os critérios de morte encefálica estão bem definidos, ainda há médicos que consideram essa situação diferente da morte. ${ }^{13}$ Quantoa enfermagem, também se tem percebido fragilidades no conhecimento das equipes quanto a aspectos do diagnóstico de ME, principais cuidados 
gerais e específicos prestados e as etapas do processo de doação de órgãos e tecidos. ${ }^{14}$

Assim, entende-se que o despreparo da equipe, além de gerar estresse profissional, sofrimento familiar, compromete a eficácia do processo, sendo fundamental a educação e aperfeiçoamento, buscando evitar tais fatores, além de possibilitar a ampliação da oferta de órgãos e tecidos para transplantes, acarretando benefícios a sociedade. ${ }^{15}$

O número insuficiente de profissionais e recursos financeiros limitados (representados pela carência na estrutura e de profissionais, como neurologistas) emergiram como principais entraves deste processo. Problemas estruturais, de financiamento e com pessoal têm marcado muitos programas de doação de órgãos, de forma que fragilidades destes componentes interferem no processo de cuidar e gera frustração entre os profissionais envolvidos na assistência ao PD. ${ }^{12}$

Outra dificuldade que os bolsistas descreveram é a abordagem familiar ineficaz, atribuindo a falta de conhecimento da família sobre o assunto, dos profissionais não serem capacitados o suficiente para lidar com a situação e a fragilidades na estrutura física do hospital, influenciando a decisão sobre a doação dos órgãos. (...) acabamos perdendo muitos casos devido à ansiedade da família. O local da abordagem também não é adequado (AE2). (...) na entrevista familiar o que mais dificulta é a disponibilidade dos médicos e uma pessoa que saiba como abordar as famílias. (...) quando os familiares são mais esclarecidos, facilita a doação (AE3). Em relação à abordagem da família a parte precária que vejo é não ir informando a realização de todo o processo, isso acaba atrapalhando e gerando a negativa, (agravado) porque o serviço já tem um atendimento precário, a família acaba se estressando e fica com raiva não do protocolo em si, mas devido ao serviço que é deficiente (AM2).

A recusa familiar se mostrou como outro entrave para os profissionais entrevistados, indo ao encontro de outras pesquisas que evidenciam a recusa como principal fator para não efetivação da doação ${ }^{5}$, sendo associada, na maioria dos casos, a não compreensão do diagnóstico de morte encefálica. ${ }^{16}$

À família do PD deve-se oferecer um cuidado especial, seja pelo fato de tal cuidado poder influenciar positivamente na aceitação para a doação, seja pela necessidade destes diante do sofrimento da perda de um ente, que em muitos casos de ME podem estar relacionados a acidentes trágicos, via de regra, envolvendo adolescentes e jovens.

Verifica-se ainda a insatisfação dos bolsistas em relação à infraestrutura hospitalar, sendo referida falta de leitos, principalmente para clientes/pacientes em investigação de ME, falta de medicamentos e insumos. Em alguns momentos, 
equipamentos básicos para UTI não estão funcionando ou não estão disponíveis em quantidades suficientes. Existem muitas dificuldades mas eu acredito que o principal seja a estrutura que temos no hospital (...), faltam alguns medicamentos e certos equipamentos estão em falta e, se existissem, melhoraria muito nosso trabalho para que pudéssemos atingir o objetivo de manter o potencial doador viável (AE3). (...) falta de profissionais qualificados (...). (...) a maioria dos clientes/pacientes que acompanhamos, não entram nem na UTI, ficam na (sala de) alta complexidade, onde falta medicamento, bomba de infusão(...) falta tudo (AM2). (...) não tem ventilador para todo potencial, não existe um leito de UTI disponível (...) então a gente, enquanto bolsista e membro da OPO, faz o que pode (...). Não se pode fazer uma gasometria no paciente na hora que quer, porque o gasômetro da UTI está calibrando ou o gasômetro da UTIpediátrica não está funcionando, então tem que o sangue ir para outro hospital (...) (AM4).

Acrescenta-se a essa problemática a precária estrutura do sistema de saúde brasileiro, caracterizada pela superlotação nas unidades de urgência e emergência, com pessoas alocadas em corredores, longo tempo de espera para o atendimento, alta tensão assistencial, grande pressão para novos atendimentos, além da falta de leitos de UTI, de equipamentos, materiais e profissionais capacitados, o que compromete não somente a assistência aos cliente/pacientes que está com possibilidade de melhora, mas também todas as ações necessárias para o desenvolvimento do processo de doação de órgãos. ${ }^{17}$

Mesmo diante dos percalços, o Brasil dispõe do maior programa público de transplantes do mundo, apresentando avanços, como aumentos expressivos do número de transplantes, embora ainda sejam insuficientes. $^{18}$

\section{CONCLUSÕES}

As OPO configuram-se como espaço privilegiado para a veiculação de novos saberes e práticas para os estudantes, mediante a temática sobre atenção a pessoa em ME e ao PD ser tratada de forma incipiente na graduação em saúde.

A temática atenção ao potencial doador de órgãos deve ser melhor abordada na formação em saúde, com um enfoque nas questões fisiológicas, deontológicas e éticas envolvidas no processo morte/morrer.

Embora a OPO que serve de cenário ao estudo apresente avanços em relação ao número de notificações, captações e transplantes de órgãos, há que se atentar para as fragilidades evidenciadas nas dimensões estrutural, recursos humanos, logística e financeira, uma vez que, provavelmente, interfiram negativamente no número de notificações, na manutenção do PD, na captação ou em transplantes de órgãos ocorridos no hospital. 
O estudo apresenta como limitação seu aspecto regional, tornando limitada a possibilidade de generalizações.

Diante do exposto, esta pesquisa suscita estudos futuros para que se quantifiquem os impactos da sujeição do processo aos entraves apontados.

\section{REFERÊNCIAS}

1. Wijdicks EFM. The diagnosis of brain death. N Engl J Med [Internet]. 2001 Apr [cited 2015 Oct 12];344(16):1215-21. Available from: http://www.nejm.org/doi/full/10.1056/NEJM 200104193441606

2. Conselho Federal de Medicina (CFM). Resolução CFM n ${ }^{\circ}$ 1.480/1997. Critérios para diagnóstico de morte encefálica. Brasília (Brasil): CFM; 1997. [Cited 2012 jan 13] Available from: http://www.portalmedico.org.br/resolucoes/c fm/1997/1480_1997.htm

3. Knobel E, Laselva CR, Moura Junior DF. Terapia intensiva: enfermagem. São Paulo: Atheneu; 2009.

4 Registro Brasileiro de Transplantes (RBT). Dimensionamento dos Transplantes no Brasil e em cada estado (2006-2013). São Paulo: Associação Brasileira de Transplante de Órgãos (ABTO); 2013.

5. Freire ILS, Vasconcelos QLDAQ, Torres GV, Araújo EC, Costa IKF, Melo GSM. Estrutura, processo e resultado da doação de órgãos e tecidos para transplante. Rev Bras Enferm

[Internet]. 2015 Sep-Oct [cited 2016 Jun 9]; 68(5): 837-45. Available from: http://www.scielo.br/pdf/reben/v68n5/00347167-reben-68-05-0837.pdf

6 Santa Casa de Misericórdia de Sobral (SCMS). 2014. [cited 2015 Apr 20]. Available from:
http://www.stacasa.com.br/NoticiasVisualizar .php?id_noticias $=36$

7. Jacob, EK; Shaw, D. Sociocognitive perspectives on representation. Annual Review of Information Science and technology (ARIST) [Internet]. 1998 [cited 2015 Apr 20]; 33:131-85. Available from: http://eric.ed.gov/?id=EJ610154

8 Lima AAF, Silva MJP, Pereira LL. Sofrimento e contradição: o significado da morte e do morrer para enfermeiros que trabalham no processo de doação de órgãos para transplante. Enfermería Global [Internet]. 2009 Feb [cited 2015 Jun 22];15(1):1-17. Available from: http://scielo.isciii.es/pdf/eg/n15/pt_clinica1.p $\underline{\text { df }}$

9. Albuquerque FNA, Silva LMS, Borges MCLA, Janebro ASI, Lima LL. Organs and tissues transplantation: analysis of nurses' performance in the process of donation and capture. R. Pesq: Cuid Fundam online [Internet]. 2011 [cited 2016 Jun 9]; 3(1):1739- 46. Available from: http://www.seer.unirio.br/index.php/cuidadof undamental/article/view/1278/pdf_372

10 Garcia CD, Goldani JC, Neumann J. et al. Importância do programa educacional de doação e transplante em escolas médicas. J Bras Transpl [Internet]. 2009 Jan-Mar [cited 2015 Aug 20];12(1):1049-1051. Available from: http://bibliofarma.com/importanciado-programa-educacional-de-doacao-etransplante-em-escolas-medicas/

11 Chehuen Neto JA. Estudantes de Medicina da UFJF e doação de órgãos para transplante. HU Revista [Internet]. 2012 JanMar [cited 2015 Aug 21];38(1):45-52. Available

from: http://hurevista.ufjf.emnuvens.com.br/hurevi sta/article/viewFile/1930/730

12 Freire ILS, Vasconcelos QLDAQ, Melo GSM, Torres GV, Araújo EC, Miranda FAN. Facilitating aspects and barriers in the effectiveness of donation of organs and tissues. Texto Contex-Enferm [Internet]. 2014 Out-Dec [cited 2016 Feb 9];23(4):92534. Available

from: 
http://www.scielo.br/pdf/tce/v23n4/pt_01040707-tce-23-04-00925.pdf

13 Moraes EL, Santos MJ, Merighi MAB, Massarollo MCKB. Experience of nurses in the process of donation of organs and tissues for transplant. Rev Latino-Am Enfermagem [Internet]. 2014 Mar-Apr [cited 2016 Jun 9];22(2):226-33. Available from: http://www.redalyc.org/articulo.oa?id=28143 $\underline{0669008}$

14. Freire ILS, Mendonça AEO, Freitas MB, Melo GSM, Costa IKF, Torres GV. Comprehension the nursing team on brain death and organ donation Enferm Global [Internet]. 2014 Oct [cited 2016 Jun 9]; 36:194-207. Available from: http://scielo.isciii.es/pdf/eg/v13n36/pt_admin istracion1.pdf

15 Freire ILS, Mendonça AEO, Pontes VO, Vasconcelos QLDAQ, Torres GV. Morte encefálica e cuidados na manutenção do potencial doador de órgãos e tecidos para transplante. Rev Eletr Enf [Internet]. 2012 Oct/Dec [cited 2016 Jun 9];14(4):903-12. Available from: http://www.fen.ufg.br/revista/v14/n4/v14n4a 19.htm

16 Rosário EN; Pinho LG, Oselame GB, Neves EB. Recusa familiar diante de um potencial doador de órgãos. Cad Saúde Colet [Internet]. 2013 [cited 2016 Jun 9];21(3):260-6. Available from: http://www.scielo.br/pdf/cadsc/v21n3/v21n3 a05.pdf

17 Bittencourt RJ; Hortale VA. Intervenções para solucionar a superlotação nos serviços de emergência hospitalar: uma revisão sistemática. Cad Saúde pública [Internet]. 2009 Jun [cited 2015 Jul 21];25(7):1439-54. Available from: http://www.scielosp.org/pdf/csp/v25n7/02.pd f

18 Associação Brasileira de Transplante de Órgãos. Perguntas e respostas sobre doação de órgãos [Internet]. São Paulo 2015 [cited 2015 Jul 15]. Available from: http://www.abto.org.br/abtov03/default.aspx? $\underline{\mathrm{mn}=477 \& \mathrm{c}=918 \& \mathrm{~s}=0 \& \text { friendly=doacao-de- }}$ orgaos-e-tecidos

Recebido em: 05/04/2016

Aprovado em: 30/06/2016

Publicado em: 31/07/2016 